\title{
Virtual Environments in Higher Education - Immersion as a Key Construct for Learning 4.0
}

http://dx.doi.org/10.3991/ijac.v9i2.6000

\author{
Daniela Janssen, Christian Tummel, Anja Richert and Ingrid Isenhardt \\ RWTH Aachen University, Aachen, Germany
}

\begin{abstract}
In light of the increasing technological developments, working life and education is changing and becoming more complex, interconnected and digital. These changed circumstances require new and modified competences of future employees. Education has to respond to the changing requirements in working life. To prepare for this, a technological-oriented teaching and learning process as well as gaining practical experience is crucial for students. In this context, Virtual Reality (VR) technologies provide new opportunities for practical experience in higher education, where they can further intensify the students learning experiences to a more immersive and engaging involvement in the learning process. To evaluate the potential of immersive virtual learning environments (VLE) for higher education and to understand more deeply which kind of experiences students gain while learning in immersive virtual environments (VE) an experimental research study is carried out. The paper describes education in light of industry 4.0 first and gives an overall view of immersive learning and the role of VR Technologies. Then the user study to measure user experience (UX) in immersive VLE is presented. Preliminary results are outlined and discussed with a view of further research.
\end{abstract}

Index Terms-immersive learning, immersion, user experience, virtual learning environment, virtual reality

\section{INTRODUCTION: EDUCATION AND LEARNING IN LIGHT OF INDUSTRY 4.0}

Digitization increasingly influences all areas of daily life because technology is an integral part of interaction, learning and knowledge acquisition [1]. New technological opportunities arise due to the developments driven by Industry 4.0. The term Industry 4.0 has emerged in Germany within the high-tech strategy of the German government in order to demonstrate the potential of the fourth industrial revolution [2]. Industry 4.0, also known as the factory of the future, implies that most of the processes and products are digitalized and automated [3]. This is based on digital intelligent, cross-linked systems, which allow self-organized production: humans, machines, systems, logistics and products communicate and cooperate directly in Industry 4.0 [4].

Thus, working processes and contents, competences of employees as well as education and training are also changing [5]. New forms of cooperation between humans and technology emerged which lead to new possibilities as well as new challenges in all sectors - from education to working life. The given demands on employees will increase because processes become more complex, interconnected and digital. Currently and in the future, lifelong learning, the ability to think interdisciplinary as well as the development of IT competences are becoming basic requirements of employees, in order to ensure the employability of working people, not only in technology oriented careers $[3 ; 6]$.

Alongside the increased networking and digitization, new ways of education are required to allow future employees to react flexible to the new challenges and demands of a digitized working environment [6]. A technological-oriented focus of education, reflectivity through the conveyance of theoretical knowledge and the experience of practical and problem-oriented application gain an increased importance in all sectors of education [3].

Considering these developments, especially highly qualified employees are requested in future. Hence, the adaption of education, in particular higher education, to the changed conditions due to Industry 4.0 is needed [7], because, , [t] he current model of pedagogy, which is at the heart of the modern university, is becoming obsolete. It is increasingly failing to meet the needs of a new generation of students who are about to enter the global knowledge economy." [8]. This new generation, also often referred to as ,digital natives ${ }^{61}$ or , millennial generation' is at college-age which means these people are already using internet for information acquisition, entertainment and as a communication tool [7]. Jonas [9] adds, "[t]he 'Millennial generation' certainly has advanced technological needs [...]. Consequently, students are changing, the content that needs to be taught is changing, and even the classroom environment (e.g. technology) is changing, so therefore, pedagogy must change." In recent years, new media as well as new teaching and learning formats like flipped classroom or MOOCs have entered higher education. However, the potential of digitization for higher education is not yet exhausted [7].

At the same time, universities are facing new challenges like high numbers of students up to 2.000 in one lecture, especially in STEM disciplines, accompanied by overcrowded lecture halls, in which students cannot participate in an active way. These challenges also require new teaching and learning formats, where technological media can contribute didactically to the learning outcomes.

The shift in education from classroom sessions to virtual education is gaining more significance. Especially in technologically oriented study fields, the practical experience of education content is often conducted in real laboratory experiments, which do not meet the requirements of Industry 4.0. The demand of having practical experiences in such study fields is increasing due to the ongoing pro-

\footnotetext{
${ }^{1}$ Digital Natives are referred to persons who have grown up with modern technology like computers, internet and mobile phones [7, p. 50].
} 
cess of technological developments and the constantly changing circumstances [10].

Because of the increasing numbers of students, not all of them get the opportunity to make practical experiences of theoretically acquired knowledge and skills. Aside from that, due to high costs, complexity or their dangerous nature, some areas of studies are not possible in real laboratories. Specifically, virtual environments (VE) provide the opportunities for experiential learning outside the lecture halls for all students at any time.

In this context, Virtual Reality (VR) technologies provide new opportunities for practical experience in higher education, where they facilitate a more natural experience in a VE. Moreover, VEs provide a hazard-free, explorative learning and a visualization of complex and abstract processes and real-phenomena for students [11]. Adding VEs and VR in higher education provide students the opportunity of the

- experience of theoretical knowledge

- use and application of technological media

- virtualization of processes

- in order to be prepared for the future working environment in a field of industry 4.0.

\section{IMMERSIVE LEARNING IN HIGHER EDUCATION}

Virtual Reality (VR) is seen as a future technology, which gains an increasing importance in industry and research. The progress in this area is driven by the rapid growth of hardware and technology, for example new interaction tools and tracking systems [12]. The technological advances and the growing availability of VR technology, like head-mounted displays (HMD), facilitate the access to universities because of their easier use and the decreasing costs of HMDs.

Hoffmann \& Hu [13] define VR as a "highly interactive and dynamic form of simulation in which a computergenerated world or environment can be 'entered', and the three-dimensional (3-D) objects within it 'explored' using visual, aural, and haptic (touching) senses." VR can be considered from different perspectives [12]:

- focus on technological aspects (3D content)

- VR as a new way of Human-Computer Interaction (HCI)

- Mental or psychological experience of VR

With regard to learning, mainly the second and third perspective is essential. In order to fulfill the students' learning requirements, the communication and interaction between immersive hardware and students have to be improved.

VR technologies are attributed with an immersive effect, which initially is caused by technological effects. Immersion is the central element of VR, which distinguished VR from other Human-Computer interfaces or media [12]. One central assumption in this context is that VR technology leads to greater immersion in the VE and in turn higher immersion leads to better learning outcomes [14].

To understand immersion, there are two existing perspectives of immersion: a technical and a user or mental perspective. The technology capability of immersion of a VR system implies that the user is surrounded by the VR so that barriers between the virtual world and the user have been removed. This leads to a greater level of users' attention and focusing [15].

The users' mental experiences in a VR environment are generally summarized by the term 'user experience' (UX), which can further be subdivided into certain theoretical constructs like immersion, presence and flow, which are used in the following.

A widespread definition of immersion is from Murray [16], who defines it as a state, in which a user is surrounded by another reality claiming his full attention. Witmer \& Singer [14] outline immersion as a "psychological state" and state that the "degree to which they feel immersed in the VE [will increase]" by effectively isolating users from the real world. Furthermore, they assume that a "VE that produces a greater sense of immersion will produce higher levels of presence." Wirth \& Hofer [17] even share this view. In contrast to this psychological perspective, Slater \& Wilbur [18] define immersion as a technical characteristic of a VR system and understand presence as a consequence of an immersive technology.

Presence is defined ,as the subjective experience of being in one place or environment, even when one is physically situated in another" [14]. In context of VE, presence means the experience of the VE rather than the physical [14]. The concept has its origin in the technology research at the beginnings of VR in 1970. Presence is the most influenced and researched concept in the field of VE. In contrast to immersion, presence is commonly understood as a user variable and not a technological characteristic.

Beside media factory influencing presence, also individual-related variables, like personality traits and demographic factors influence presence [19]. Increased time spent in the VE is another impact factor, which can both raise presence because of adjustment and knowing as well as reduce presence due to negative effects intensify over time [20]. The examination of the relationship between presence and performance is mostly based on correlation studies. Therefore, possible factors affecting presence and performance have to be experimentally controlled in further research studies [20]. Wirth \& Höfer [17] add that media, which has particular lots of features, which promotes presence, referred to as immersive. They have a high potential of immersion. The greater the immersion of a medium, the more likely is that the user experiences presence in the VE [21].

Flow is defined as a reflection-free merging in smooth ongoing activities that have been under control despite high strain [22]. Moreover, someone is in a state of flow, when requirements and competences are balanced [23]. Flow is the most general concept of all three constructs, because the experiences are not limited to media use, but to a series of activities [24]. The concept has its origin in happiness research and was originally used in daily activities [22]. Research studies have shown that the state of flow has an influence on information processing, cognitive load and physiological processes [25].

Considering the state of the art, it can be assumed that technologies, which have a greater level of immersion, lead to greater UX when users interact with the VE. The question arises to what extent immersion influences task performance in VLE and how immersion can support the learning process in a positive way. Moreno \& Mayer [26] state that " $[\mathrm{t}]$ he fundamental idea is that students who learn by participating in the learning task with a higher 
sense of being in the environment may learn more deeply than students who learn by participating in the learning task as observers."

Applying VR technologies in teaching and learning scenarios can further increase the students' learning experience to a more immersive and engaging involvement in learning processes [27]. The immersion into a virtual world offers students the potential to experience virtual objects and to interact with the environment. Thus, a constructivist perspective of the learning process can be encouraged, in which students learn in an active, selfcontrolled way in situational, problem-oriented contexts. VEs provide a setting, which facilitates a more personalized learning process matching students' requirements and offering a higher learning autonomy [28]. To confirm this assumption further empirical evidence is necessary, especially if immersive VLE should be an appropriate tool for education. Therefore, the presented user study is undertaken.

\section{USER STUDY: MEASURING USER EXPERIENCE IN IMMERSIVE VIRTUAL LEARNING ENVIRONMENTS}

\section{A. Study Design}

In this study, the research focus is placed on the effects of user traits and user interface characteristics on UX, activation and task performance on students. The main purpose of the study is to be able to measure UX in immersive VLEs and their relation to task performance. Thereby, more evidence is given how users discover immersive VLEs and which aspects influence the task performance in a VE (Fig. 1).

To understand which user and user interface factors influence UX, activation and task performance within the developed VLE a controlled experiment is carried out. The controlled experiment is set up as an experimental research design (Fig. 2).

\section{B. Hardware set-up}

In terms of the hardware set-up, there are two experimental hardware conditions: immersive and nonimmersive. The immersive condition includes the HeadMounted Display (HMD), (in this study, the Oculus Rift DK 2 was used), whereas the non-immersive condition is a computer version without HMD. Participants are randomly assigned to experimental condition (HMD) and control condition (computer).

\section{1) Computer as the control condition}

A dell computer with a 27 inch display and a $1920 \mathrm{x}$ 1200 resolution was used in this study. During the experiment, participants control their field of view with a mouse, whereas they control their locomotion using a keyboard and the WASD-keys. To go forward and backward, they use W/S keys, while they use A/D keys in order to go left and right in the VLE.

\section{2) Oculus Rift as the experimental condition}

In this study, the Oculus Rift Developers Kit DK 2 is used, which is the second development kit version. The Oculus Rift is a HMD, which means that participants wear a mobile visualization and interaction system in the form of a helmet or a data glasses on their head. The Oculus Rift has a 5.7 inch screen with a resolution of $1920 \times 1080$.

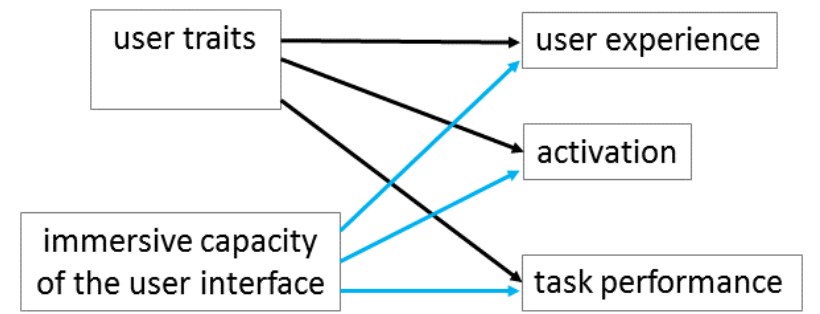

Figure 1. Effects between user traits, user interface characteristics and $\mathrm{UX}$, activation and task performance

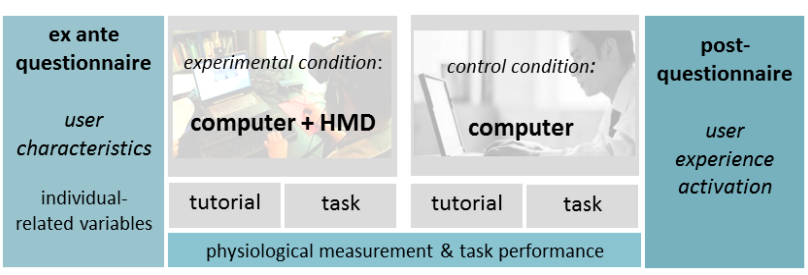

Figure 2. Study design

The installed sensors in the glasses track the rotation, bending, lifting and lowering of the head as well as the position in the room. A camera recorded the infrared LEDs within the glasses [29]. The main purpose of HMDs is to shift the user into a virtual reality [12]. The locomotion in the VLE with the Oculus Rift is equal to the computer with the WASD keys. As distinguished from the computer, the Oculus Rift controls the field of view.

\section{Minecraft as the setting for the virtual learning environment}

For the analysis, the open-world sandbox game Minecraft was designed as a VLE. It is suitable for the use in different academic learning contexts, like engineering, physics or geography as well as for nontechnical learning scenarios like creativity, teamwork or specific skills [30]. Moreover, Minecraft offers opportunities to explore a VE in a free, active and experimental way to build new objects. Programming capabilities from students or teachers are not required, which facilitates the application in education due to cost, time and personal resources. Furthermore, Minecraft has already applied successfully in learning contexts [31, 32].

In this study, the conception of Minecraft as the setting for the VLE is following the game design steps according to references [33, 34]: define the target group, define learning outcomes of the game, define the game, shape the game idea and elaborate the details (storyline), (technical) implementation of the game.

University students as well as high school students at the age of 16 to 18 constitute the target group because they are the next generation entering the job market in a few years. Consequently, they have to be prepared at an early stage in their education for the complex, digitized and constantly changing requirements. In this context, problem-solving ability gains more and more importance. In the VLE, the task to be solved is designed according to the demands of Industry 4.0. Therefore, a problem-solving task is chosen, in which participants have to solve a logistical problem task. The task is integrated in a storyline in an industrial factory setting where students are employees of a company, which produces soft drinks, especially lemonade. 
Furthermore, the definition of learning outcomes is essential for a transparent teaching and learning process. In this way, students are enabled to evaluate their decisions, actions and results in the learning process. The following learning outcomes are defined for the VLE.

1. Spatial orientation: at first students have to get an overview of the industrial area, where they have to build the driverless transportation route on rails.

2. Decision Making: after getting an overview of the area and the various possibilities to build the transportation route, they have to make a decision in terms of the requirements on the task, like efficiency and rapidity.

3. Problem solving: there are certain barriers in the industrial area, like silos or cars, which have to be considered by choosing and building the transportation route.

4. Psychomotoric skills: Students have to use the hardware appropriate and have to navigate through the virtual environment.

\section{Experimental task}

The experimental task simulates a problem-solving process. Problem-solving tasks require a self-employed, active way of finding solutions. The students' task is to build a driverless transportation route on rails in order to transport freight from a warehouse to a factory. As requirements to solve the task, participants have to construct the transportation route on rails in an efficient, resource saving and rapid way.

Before working on the task, participants have the option to enter a tutorial so that they get to know the VE and the control system for locomotion and for the field of view. In the tutorial, the participants can learn and practices the basics of using Minecraft, in particular how to lay and remove the rail tracks and how to move in the VE. The students that are in the experimental group can additionally use the tutorial to familiarize with the HMD and the immersive effect.

A specifically programmed tool, which records the following performance parameters, measures task performance: time, number of used rails, errors in form of the number of removed rails and traveled distance of each participant. Supplementary, a screen capturing software is recording the student's movement within the VLE while solving the task. To measure the physiology of the participants during the task, biofeedback sensors measure skin conductance three times during the experiment. To run a baseline measurement of each participants without engaging in any task, first a one-minute baseline is recorded in advance, which serves as a reference value to the physiological measurement during the task. After the task, a third measurement is carried out.

\section{E. Measurment and variables}

To assess the relationship between individual-related variables, immersive capacity of the user interface, UX, activation and task performance in a VLE, a set of independent and dependent variables is defined.

As independent variables, the following constructs were under study:

- Socio-demographic data, like age and gender

- Personality traits (10 Item Big Five Inventory)

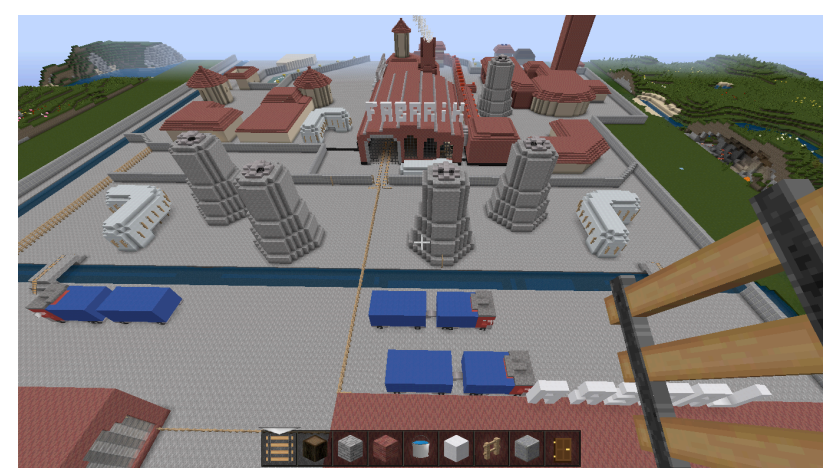

Figure 3. Screen Capture of the Experimental Scenario

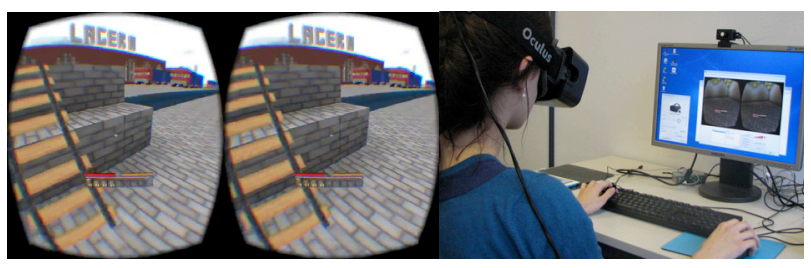

Figure 4. Screen Capture of the Experimental Research Setup

- Locus of control when interacting with technology (KUT) [35]

- Gaming behavior/ frequency of using games

- Spatial cognition (Questionnaire Spatial Strategies, QSS) [36]

- Immersive tendency (Immersive Tendency Questionnaire, ITQ) [14]

- Immersive capacity of the user interface

All variables are collected via self-report information in form of a pre-questionnaire.

As dependent variables, three variables are used:

- UX is measured via the following scales: immersion (immersive experience questionnaire, IEQ) [37], presence (Presence Questionnaire, PQ) [13], flow (Flow Short Scala, FSC) [38] and game experience (Game Experience Questionnaire, GEQ) [39].

- Activation is measured with two instruments: a questionnaire based on subjective reports as well as a psychophysiological measurement via electro dermal activity (EDA).

- Performance is measured via different parameters: time, number of used rails, errors in form of the number of removed rails and traveled distance of each participant.

UX is operationalized with the following constructs: immersion, presence, flow and game experiences. For the constructs already existing reliable and valid instruments are used which are based on subjective reports as a common method to measure UX [20]. All items of the preand post-questionnaire were answered on a six-scale, ranging from $1=$ total agree to $6=$ total agree.

To complement these, psychophysiological measurements offer an objective, non-invasive method to collect physiological activation during the experiences of a VLE [40]. Mandryk [41] has shown that physiological indications serves as an objectively indicator of UX with computer games. 
The various methods (self-report, quantitative questionnaires, objective physiological measurements) constitute a complex and detailed description of the conscious and subconscious UX of the students in the VLE.

\section{IV. SAMPLE AND RESULTS}

\section{A. Sample}

In order to examine the complete process of the study including the measuring instruments, task difficulty in the VLE as well as the technical process of the study, a pretest was conducted with 10 students between 15 and 29 (MW $=24,9 ; \mathrm{SD}=4,48 ; \mathrm{n}=7$ females). The majority of the participants are playing digital games, mostly on their smartphone to an average game time of 3.75 hours per week. Similarly, $70 \%$ of the participants have already use a VR technology twice. With regard to Minecraft, $50 \%$ of the participants have already played it, however no more than two times.

\section{B. Correlation Approach}

To gain further information regarding the relationship of the user traits, user interface characteristics and of the UX, activation and task performance an explorative approach has been used. Data were analyzed with IBM SPSS statistics software.

In consideration of a very small sample $(n=10)$, initial significant correlations between various independent and dependent variables were found. A significant correlation exists between the independent variable immersive tendency with the subscales game, involvement and focus and the dependent variables immersive experience, presence, flow and game experience (Figure 5).

Between the other independent variables and the dependent variables, no significant correlations are found in the analysis.

The dependent variable immersive experience correlates solely with the subscales negative affect, tension/ annoyance, flow, challenge and positive affect of the dependent variable game experience. The dependent variable presence shows significant correlations with flow and the subscales positive affect, competence and sensory and imaginative immersion of the GEQ. The analysis shows significant correlations between flow and presence and with the subscales positive affect, competence and sensory and imaginative immersion of the GEQ.

With a special view to user traits, the following significant correlations were found in the analysis. Participants with a higher Neuroticism (Big Five) have a lower flow experience $(\mathrm{r}=-.68, \mathrm{p} \geq .05)$, a lower value in the subscale positive affect $(\mathrm{r}=-.69, \mathrm{p} \geq .05)$, competence $(\mathrm{r}=-.75$, $\mathrm{p} \geq .05)$ and sensory and imaginative Immersion $(\mathrm{r}=-.68$, $\mathrm{p} \geq .05)$ of the GEQ. Participants with a higher openness for experiences (Big Five) have a higher value in the subscale focus of the ITQ ( $\mathrm{r}=.72, \mathrm{p} \geq .05$ ). Participants whose spatial strategy global/self-centered (QSS) is more pronounced, have a higher flow experience $(\mathrm{r}=.72, \mathrm{p} \geq .05)$, have higher values in the subscale positive affect $(\mathrm{r}=.8$, $\mathrm{p} \geq .05)$, competence $(\mathrm{r}=.78, \mathrm{p} \geq .05)$ (GEQ) and involvement $(\mathrm{r}=.66, \mathrm{p} \geq .05)$ (ITQ). Participants with a higher locus of control when interacting with technology have a lower value in the subscale negative affect of the GEQ ( $\mathrm{r}=$ $-.74, \mathrm{p} \geq .05)$.

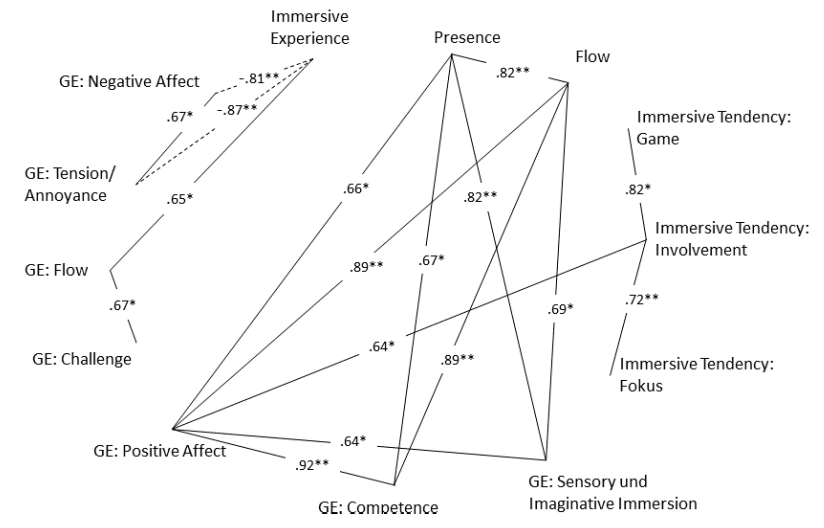

Figure 5. Correlations between immersive tendency, immersion, flow, presence and game experience $(*=$ significant at the 0.05 -level (2sided); $* *=$ significant at the 0.01 -level (2-sided); $\mathrm{n}=10$.

\section{Analysis of the Screen Recording}

During the processing of the task, a screen capture software records the movement of the students in the VLE. The recordings are analyzed qualitatively in terms of the elected strategies to build the driverless transportation route. Three different strategies are identified:

1. Provide an overview at the current position before starting the task

2. Provide an overview before starting the task while walking in the industrial area

3. Directly lay rails without getting an overview

The frequently used strategy was the second one. Six of the students gained an overview at first, by walking in the industrial area and examine the environment and barriers. Some of these students use a modified strategy. First, they went to the bridge in the area. From there they start to lay rails to the beginning, then they laid rails from the goal to the bridge. Three students used the third strategy. Without getting an overview of the area, they started the task immediately by laying rails. The quantitative analysis of the task performance have shown that the students take from 3:30 minutes up to 8 minutes to solve the task. On an average, the task is solved in 4:30 minutes. The average usage of rails lay by 130 rails. There are no significant differences in the number of used rails, neither in the immersive condition. A connection between the strategies and the task performance parameters time, number of used rails, errors in form of the number of removed rails and traveled distance of each participant could not be found. Further analysis is required in order to relate task performance, the used strategy and the UX.

\section{DISCUSSION AND FUTURE WORK}

Concerning the effects of user traits on UX in immersive VLE, the initial results have shown that there exists an impact. Particularly, users who a more uncertain, anxious or nervous characteristics experience the VLE less positive and are not as engaged as users who are a more active and open character. These results indicate that user characteristics and traits have a positive or negative key impact on the experience of VLE. Thus, it can be assumed that they have an effect on the task performance and thereby on the learning process. Further research is needed in order to investigate which user traits have a central function in this context. Wünsch et al. [24] stated that 
personality traits provide an explanatory approach how users perceive, process, evaluate and experience media. Furthermore, the immersive tendency of a user to be involved in VE has an effect of the experience of flow and how challenging a VLE could be. With the ITQ, the students that probably have the most advantages from a VLE could be recognized [14]. Consequently, statements can be made for which users immersive VLE are suitable with regard to fostering the learning process.

In contrast to literature review, there is no significant correlation between immersive tendency and presence. Witmer \& Singer [14] assumed that "[i]f high ITQ scores reflect a greater tendency to become involved or immersed, then individuals who score high on the ITQ should report more presence on the PQ when exposed to a particular VE." At this point, further research is needed.

With regard to the dependent variables and UX operationalized with the construct presence, flow, immersion and game experience, the following statements can be made. Presence and flow are linked with a positive experience of the VLE and competence, which in turn means that presence and flow have an impact on task performance in the VLE. This is line with Witmer \& Singer [14] who have shown that the PQ was positively related to measure task performances in VE. In a further step, the results of the task performance in the VLE has to be analyzed in terms of their relationship to experience presence and flow in the VLE. Moreover, flow and presence has an impact on the sensory and imaginative immersion of a user in the VLE.

A significant impact of the user interface respectively their technological immersion on the dependent variables immersion, presence, flow and game experience could not be established. At this point, in the follow-up study, the effect of the user interface on UX and task performance have to be investigated in greater depth with a larger sample.

This exploratory analysis of the pretest on the effects of immersive VLE on UX and task performance confirmed a few theoretical assumptions but also contradicted others. The correlation approach has shown initial significant correlations between independent and dependent variables, especially between the variables, which measure UX. However, these correlations cannot explain the causeeffect relationship between independent and dependent variables. Hence, these correlations have to be investigated with a larger sample in order to validate these preliminary findings. All interpretations for the given results are going to be addressed in a follow-up study. Next, the effects of the hardware on presence, flow, immersion and game experience with regard to the task performance are analyzed in more detail. Thus, a deeper insight on the participants' experiences will allow a more differentiated view on the focus of this research.

\section{OUTLOOK}

The pretest of the follow-up study has given a first insight into the psychological experience of students by solving a task in the VLE in Minecraft.

Literature review has shown that immersion is hypothesized as the key construct for better learning $[17,26]$. In order to confirm this hypothesis, further research studies are required, especially, in order to investigate the impact of user traits on UX and on task performance and how UX and task performance are interrelated.

The results of the pretest have shown that individual traits and characteristics influence the experience of a user in a VLE. Therefore, it can be expected that for some users learning in a VLE has a greater benefit than for others. It has to be assessed which user traits have an impact for example, age, gender and experience with digital games. These factors have to be identified. The follow-up study with a larger sample aims to set up user profiles in terms of immersive VLE, especially for whom immersive VLE brings an advantage in the learning process. This helps to get deeper insight into the specific preferences of students in education and their preparation for future working life.

In a further step, the teacher perspective has to be undertaken because it is challenging teachers to teach, learn and work in the virtual environment. They have to know the didactical as well as technological characteristics of VLE in order to apply them appropriate in the teaching and learning process [42]. Therefore, an important contribution for using immersive VLEs in learning scenarios in school and universities with a special view to digitalization in education can be made.

\section{REFERENCES}

[1] W. Sauter, „Digitale Lehre - die Zukunft der Hochschule?“. Blended Solutions's Blog. URL: https://blendedsolutions.word press.com/2016/01/09/digitale-lehre-die-zukunft-der-hochschule/, (18.02.2016)

[2] Q. Guo, "Learning in a Mixed Realty System in the Context of 'Industry 4.0," in Journal of Technical Education vol. 3, 2015

[3] J. Gebhard, A. Grimm, L.M. Neugebauer, „Entwicklungen 4.0 Ausblicke auf zukünftige Anforderungen an und Auswirkungen auf Arbeit und Ausbilung“, in Journal of Technical Education, vol. 3, 2015, pp. 45-61

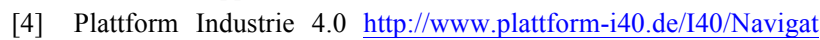
ion/DE/Industrie40/WasIndustrie40/was-ist-industrie-40.html;jses sionid=4BAE281CE880F88021E4F0B2AB86A988 (17.02.2016)

[5] A. Richert, M. Shehadeh, L. Plumans, K. Gross, K. Schuster, S. Jeschke, "Educating Engineers for Industry 4.0: Virtual Worlds and Human-Robot-Teams," IEEE Educon 2016 in press.

[6] A. Richert, W. Behrens, S. Jeschke "Industry 4.0 meets Generations $\mathrm{X}, \mathrm{Y}$ and $\mathrm{Z}$ Qualification and Training for working in new industrial age", IPW Regionaltagung 2015.

[7] J. Handke, Patient Hochschullehre. Vorschläge für eine zeitgemäße Lehre im 21. Jahrhundert, Marburg: Tectum Verlag, 2014.

[8] D. Tapscott, A.D. Williams ,Innovating the 21t Century University: It's time." in Educause Review 45, vol. 1, 2010, pp.16-29.

[9] P.M. Jonas, "Successfully Teaching with Humuorous Videos: VideagogyC http://education.jhu.edu/PD/newhorizons/Journals/ Winter2012/Jonas (19.02.20169

[10] D. Janßen, C. Tummel, A. Richert, D. Schilberg, S. Jeschke, "Pump It up! - Conception of a Serious Game Applying in Computer Science", in Proceedings of the 17th International Conference on Human-Computer Interaction (HCI 2015), vol. 529, Communications in Computer and Information Science, Cham: Springer International Publishing, pp. 253-258, 2015

[11] B. Dalgarno, J. Hedberg, "3D learning environments in tertiary education", in Ascilite '01: Meeting the crossroads, pp. 33-36 2001.

[12] R. Dörner, W. Broll, P. Grimm, B. Jung, "Virtual and Augmented Reality (VR/AR). Grundlagen und Methoden der Virtuellen und Augmentierten Realität", Berlin Heidelberg: Springer-Verlag, 2013.

[13] H. Hoffmann, D. Vu, "Virtual Reality: Teaching Tool of the Twenty-first Century?", in Perspectives on computing and medical education (C.P. Friedmann), 1997, p. 1076-1081. http://dx.doi.org/10.1097/00001888-199712000-00018 
[14] B.G. Witmer, M. J. Singer, "Measuring Presence in Virtual Environments: A Presence Questionnaire", in Presence: Teleoperators and Virtual Environments, vol. 7, 1998, pp. 225-240. http://dx.doi.org/10.1162/105474698565686

[15] L. J. Issing, P. Klimsa, ,Information und Lernen mit Multimedia und Internet. Lehrbuch für Studium und Praxis“. Weinheim: Beltz PVU, 2002.

[16] J. Murray, "Hamlet on the Holodeck: The Future of Narrative in Cyberspace", 1997, Cambridge: MIT Press, pp. 98-99.

[17] W. Wirth, M. Hofer, „Präsenzerleben - eine Einführung aus Medienpsychologischer Perspektive“, in Montage AV, vol. 17, 2009, pp. $159-175$.

[18] M. Slater, S. Wilbur, "A Framework for Immersive Virtual Environments (FIVE): Speculations on the Role of Presence in Virtual Environments", in Presence: Teleoperators and Virtual Environments, vol. 6, 1997, Cambridge: MIT Press pp. 603-616.

[19] U. Mögerle, S. Böcking, W. Wirth, H. Schramm, „Unterhaltungserleben in virtuellen Medien. Die Rolle von Medien und Rezipienteneigenschaften beim Entstehen von Spatial Presence“, in H. Schramm, W. Wirth, H. Bilandzic, ,Empirische Unterhaltungsforschung. Studien zu Rezeption und Wirkung von medialer Unterhaltung", Baden: Baden: Nomos, 2006, pp. 87-106.

[20] E. B. Nash, G. W. Edwards, J. A. Thompson, W. Barfield, "A Review of Presence and Performance in Virtual Environments", in International Journal of Human-Computer Interaction, vol. 12, 2000, pp. 1-41. http://dx.doi.org/10.1207/S15327590IJHC1201 1

[21] T. Schubert; J. Crusius, "Five Theses on the Book Problem. Presence in Books, Film, and VR", in: PRESENCE 2002 - Proceedings of the Fifth 38 International Workshop on Presence.", F. R. Gouveia, F. Biocca. Porto: Universidad Fernando Pessoa, 2002, pp. 53-59.

[22] M. Csikszentmihalyi, "Flow: The Psychology of Optimal Experience. Harper and Row", New York, 1990.

[23] J.H. Brockmyer, C.M. Fox, K.A. Curtiss, E. McBroom, K.M. Burkhart, J.N. Pidruzny, "The development of the Game Engagement Questionnaire: A measure of engagement in video gameplaying", in Journal of Experimental Social Psychology, 2009, pp. 624-634. http://dx.doi.org/10.1016/j.jesp.2009.02.016

[24] C. Wünsch, H. Schramm, V. Gehrau, H. Bilandzic, Handbuch Medienrezeption. Baden-Baden: Nomos, 2014. http://dx.doi.org/10.5771/9783845260389

[25] J. Keller, A. Landhäußer, „Im Flow sein. Experimentelle Analysen des Zustands optimaler Beanspruchung", in Psychologische Rundschau, vol. 62, 2011, pp. 213-220. http://dx.doi.org/10.1026/0033$3042 / \mathrm{a} 000058$

[26] R. Moreno, R.E. Mayer, "Learning Science in virtual reality multimedia environments: Role of methods and media", Journal of Educational Psychology, vol. 94, 2002, p. 601 http://dx.doi.org/10.1037/0022-0663.94.3.598

[27] L. Chittaro, F. Buttussi, "Assessing Knowledge Retention of an Immersive Serious Games vs. a Traditional Education Method in Aviation Safety", in IEEE Transactions on Visualization and Computer Graphics, vol. 21, 2015, pp. 529-538. http://dx.doi.org/10.1109/TVCG.2015.2391853

[28] M. Chau, A. Wong, M. Wang, S. Lai, K.W.Y Chan, T.M.H. Li, et al., "Using 3D virtual environments to facilitate students in constructivist learning" in Decision Support Systems, vol. 56, 2013, pp. 115-121. http://dx.doi.org/10.1016/j.dss.2013.05.009

[29] J.K. Janssen, S. Porteck, „Willkommen in der Virtualität", in $c^{\prime} t$ heft 201, 2014, pp. $16-19$.

[30] D. Short, "Teaching scientific concepts using a virtual world Minecraft", in The Journal of the Australian Science Teachers Association, vol. 58,2012 , pp. 55-58.

[31] C. Schifter, M Cipollone, "Minecraft as a teaching tool: One Case study", in Proceedings of Society for Information and Technology \& Teacher Education International Conference. Chesapeake, VA: AACE 2013, pp. 2951-2955.

[32] A. Reem, J. Bana, I. Knight, E. Benson, O. Afolabi, A. Kerr, P. Blanchfield, G. Hopkins, G., "Design of a Math Learning Game Using a Minecraft Mod", in Proceedings of the European Conference on Games Based Learning, 2014.

[33] M. Pivec, M. Moretti, Game-based Learning: Discover the pleasure of Learning. Pabst Science Publishers, 2008
[34] R. Morsi, E. Jackson, "Playing and Learning? Educational Gaming for Engineering Education", in IEEE Frontiers in Education Conference - Global Engineering: Knowledge without Borders, Opportunities without passports, 2007, pp. F2H-1 - F2H-6.

[35] G. Beier, „Kontrollüberzeugungen im Umgang mit Technik“. Report Psychologie 9/99, 1993, pp. 684-694.

[36] S. Münzer, C. Hölscher, „Entwicklung und Validierung eines Fragebogens zu räumlichen Strategien“, in Diagnostica 57 (3), 2011, pp. 111-125.

[37] C. Jennett, A.L. Cox, P. Cairns, S. Dhoparee, A. Epps, T. Tijs, T. et al., "Measuring and defining the experience of immersion in games", in International Journal of Human-Computer Studies, 66 (9), 2008, pp. 641-661. http://dx.doi.org/10.1016/j.jijhcs. 2008.04.004

[38] F. Rheinberg, R. Vollmeyer, S. Engeser, ,Die Erfassung des FlowErlebens", in J. Stiensmeier-Pelster, F. Rheinberg, Diagnostik von Selbstkonzept, Lernmotivation und Selbstregulation. Göttingen: Hogrefe, 2003, pp. 261-279.

[39] W.A. IJsselsteijn, Y.A.W. de Kort, K. Poels, "The Game Experience Questionnaire: Development of a self-report measure to assess the psychological impact of digital games". Manuscript in preparation.

[40] J. M. Kivikangas, G. Chanel, B. Cowley, I. Ekman, M. Salminen, S. Järvelä, N. Ravaja, N., "A review of the use of psychophysiological methods in game research", in Journal of Gaming \& Virtual Worlds, vol. 3, 2011, pp. 181-199.

[41] R. Mandryk, "Physiological measures for game evaluation", in K. Isbister, N. Schaffer, Game Usability: Advancing the player experience. Morgan Kaufmann, Burlington, 2008.

[42] A. Richert, L. Plumanns, K. Gross, K. Schuster, S. Jeschke, "Learning 4.0. Virtual Immersive Engineering Education", in Digital Universities: International Best Practices and Applications, ISSUE 2015/2.

\section{AUTHORS}

Daniela Janssen is researcher in the research group "Agile Management and eHumanties" at the Center for Learning and Knowledge Management (ZLW) in the institute cluster IMA/ZLW \& IfU at RWTH Aachen University, Aachen, Germany (e-mail: daniela.janssen@imazlw-ifu.rwth-aachen.de)

Dr. Ing. Dipl.-Inform. Christian Tummel is researcher and leader of the research group "Agile Management and eHumanties" at the Center for Learning and Knowledge Management (ZLW) in the institute cluster IMA/ZLW \& IfU at RWTH Aachen University, Aachen, Germany (e-mail: christian.tummel@ima-zlw-ifu.rwthaachen.de).

Prof. Dr. phil Anja Richert is junior professor for agile management at the faculty for mechanical engineering and managing director of the Center for Learning and Knowledge Management (ZLW) in the institute cluster IMA/ZLW \& IfU at RWTH Aachen University, Aachen, Germany (e-mail: anja.richert@ima-zlw-ifu.rwthachen.de)

apl.-Prof. Dr. habil. Ingrid Isenhardt is the director deputy head of the institute cluster IMA/ZLW \& IfU at RWTH Aachen University, Aachen, Germany (e-mail: Ingrid.isenhardt@ima-zlw-ifu.rwth-aachen.de).

IMA - Institute for Information Management in Mechanical Engineering ZLW - Center for Learning and Knowledge Management IfU - Institute for Management Cybernetic

Submitted 15 March 2016. Published as resubmitted by the authors 26 April 2016. This article is an extended and modified version of a paper presented at the the International Conference on E-learning in the Workplace 2016 (ICELW 2016), held in June 2016, at Columbia University in New York, NY, USA. 